\title{
Results of a quality improvement initiative reassessing an institutional lumbar drain infection prevention protocol
}

\author{
Ariane Lewis, MD, ${ }^{1,2}$ Aaron Rothstein, MD, ${ }^{1}$ and Donato Pacione, MD² \\ Departments of ${ }^{1}$ Neurology and ${ }^{2}$ Neurosurgery, NYU Langone Medical Center, New York, New York
}

OBJECTIVE The objective of this study was to determine the effects of a quality improvement initiative in which daily antibiotics and daily sampling of cerebrospinal fluid (CSF) were discontinued for patients with lumbar drains.

METHODS The frequency of surgical site infections (SSIs), antibiotic-related complications (development of Clostridium difficile infection [CDI] and growth of resistant bacteria), and cost for patients with lumbar drains were compared during 3 periods: 1) prolonged prophylactic systemic antibiotics (PPSA) until the time of drain removal and daily CSF sampling (September 2013-2014), 2) PPSA and CSF sampling once after placement then as needed (January 2015-2016), and 3) antibiotics only during placement of the lumbar drain and CSF sampling once after placement then as needed (April 2016-2017).

RESULTS Thirty-nine patients were identified in period 1, 53 patients in period 2, and 39 patients in period 3 . There was no change in the frequency of SSI after discontinuation of routine CSF testing or PPSA ( $0 \%$ in period $1,2 \%$ in period 2 , and $0 \%$ in period 3). In periods 1 and 2, 3 patients developed infections due to resistant organisms and 2 patients had CDI. In period 3, 1 patient had an infection due to a resistant organism. The median cost of CSF tests per patient was $\$ 100.68$ (interquartile range [IQR] \$100.68-\$134.24) for patients in period 1 and \$33.56 (IQR \$33.56-\$33.56) in periods 2 and $3(p<0.001)$. The median cost of antibiotics per patient was $\$ 26.32$ (IQR \$26.32-\$30.65) in periods 1 and 2 and $\$ 3.29$ (\$3.29-\$3.29) in period 3 ( $p<0.001)$. The cost associated with growth of resistant bacteria and CDI was $\$ 91,291$ in periods 1 and 2 and $\$ 25,573$ in period 3 .

CONCLUSIONS After discontinuing daily antibiotics and daily CSF sampling for patients with lumbar drains, the frequency of SSI was unchanged and the frequency of antibiotic-related complications decreased.

https://thejns.org/doi/abs/10.3171/2017.11.SPINE171023

KEYWORDS antibiotics; lumbar drain; surgical site infection; prophylaxis

$\mathrm{L}$ UMBAR drain placement is a common neurosurgical procedure to facilitate cerebrospinal fluid (CSF) drainage. ${ }^{24}$ There is a $3 \%-12 \%$ risk of surgical site infection (SSI) after placement of a lumbar drain. SSI can increase morbidity and mortality. ${ }^{10,15,24}$ Few studies address infection prevention for patients with lumbar drains, but extrapolating from the literature on patients with external ventricular drains, 2 strategies to avoid SSI are 1) the use of prolonged prophylactic systemic antibiotics (PPSA) until the time of drain removal and 2) daily CSF sampling to monitor for development of infection..$^{13,15,16,24}$ The role for these practices in the lumbar drain population is not well examined, and both are associated with risks: ${ }^{17}$ PPSA use increases the risk of Clostridium difficile infection (CDI) and growth of resistant bacteria, which can lead to delayed recovery, risk of additional surgery, increased length of stay, escalated cost of admission, and death:,111,12,14,20-22 and frequent sampling of CSF can increase the risk of develop- ment of SSI due to introduction of bacteria into the sterile system while CSF is collected. ${ }^{26,27}$

Patients with lumbar drains at the authors' institution previously were given PPSA and had CSF sampled daily. In the past few years, the Neurosurgical Quality Improvement Committee instituted changes to the lumbar drain management protocol, and at present, antibiotics are only given and CSF is only sampled at the time of drain placement or if there is suspicion for infection. In the present analysis, the effects of these quality improvement initiatives were retrospectively evaluated by reviewing the frequency of SSI, CDI, and growth of resistant bacteria before and after the protocol changed. Additionally, the savings associated with these protocol changes were calculated.

\section{Methods}

\section{Infection Prevention Protocol}

At the authors' institution, prior to October 2014, pa- 
tients with lumbar drains had daily CSF samples sent to check cell counts, glucose, protein, and bacterial culture. These patients were also administered prophylactic antibiotics (cefazolin or vancomycin) from the time of drain placement until the time of drain removal. In October 2014, the Neurosurgery Quality Improvement Committee adjusted institutional practice such that CSF samples were only sent at the time of lumbar drain placement and as needed if there was concern for meningitis. In February 2016, the Committee further modified protocol such that antibiotics were administered only at the time of drain placement, unless there was concern for infection. No other changes were made to routine infection prevention practices, including prepping the site with chlorhexidine; covering the surgical site with a large drape; donning a cap, mask, and sterile gown and gloves; and dressing the surgical site with a large sterile Tegaderm (3M Products).

\section{Patient Selection/Data Collection}

We collected data from a quality improvement database for patients with lumbar drains during 3 periods: 1) daily antibiotics and daily CSF sampling (September 2013-2014),2) daily antibiotics and CSF sampling once after placement then as needed (January 2015-2016), and 3 ) antibiotics only during placement of the lumbar drain and CSF sampling once after placement then as needed (April 2016-2017). Only patients older than 17 years were included in the database. Patients were excluded if they 1) received antibiotics during the hospitalization in which the lumbar drain was placed for any reason other than prophylaxis, 2) received antibiotics other than cefazolin or vancomycin, or 3) were transferred to another hospital for continuation of care.

Deep and superficial SSIs were defined using Centers for Disease Control criteria. A deep SSI is present in the setting of one or more of the following: 1) purulent drainage from a deep incision, 2) an incision that dehisces or is intentionally debrided and is culture positive or not cultured AND is associated with fever $>38^{\circ} \mathrm{C}$ or localized pain, or 3) an abscess at the surgical site. A superficial SSI is present in the setting of one or more of the following: 1) purulent drainage from a superficial incision; 2) organisms isolated from a culture of a superficial incision; or 3 ) an incision that was debrided and is culture positive or not cultured AND is associated with pain, swelling, redness, or heat. ${ }^{7}$ Growth of resistant organisms was defined as growth of an organism that was resistant to the prophylactic antibiotic that was administered (cefazolin or vancomycin).

\section{Cost Calculations}

As per a prior analysis of savings associated with discontinuation of prophylactic antibiotics for patients with subdural and subgaleal drains, cost was calculated as follows: $\$ 3.29$ for a $1-\mathrm{g}$ bag of cefazolin, $\$ 3.10$ for a $1-\mathrm{g}$ vial of vancomycin, \$7286 for CDI, and \$25,573 for growth of a resistant organism. ${ }^{18,19,22}$ Cost of a full set of routine CSF tests at the institution is $\$ 33.56$ ( $\$ 7.03$ for CSF cell count, $\$ 6.43$ for CSF glucose, $\$ 6$ for CSF protein, and $\$ 14.10$ for CSF Gram stain and culture).

\section{Data Evaluation}

Chi-square, likelihood ratios, Kruskal-Wallis, and ANOVA tests were used as appropriate. All statistical analyses were performed using SPSS 21 (IBM Corp.). A p value $<0.05$ was considered statistically significant. This study was approved by the institutional review board.

\section{Results \\ Patients}

During the 3 study periods, 147 patients with lumbar drains were identified. Sixteen patients were excluded from analysis (12 who received antibiotics for known or suspected infections during the admission in which the lumbar drain was placed, 3 who were transferred to other hospitals for further care, and 1 who was given clindamycin for prophylaxis due to multiple allergies). One patient from period 1 had only one set of CSF tests sent for unclear reasons, so her data were included in period 2. One patient from period 2 refused antibiotics, so her data were included in period 3 . One patient in period 3 received prophylactic antibiotics throughout the duration of his lumbar drain for unclear reasons, so his data were included in period 2. Thus, $\mathrm{n}=39$ in period $1, \mathrm{n}=53$ in period 2 , and $\mathrm{n}=$ 39 in period 3 . The majority $(68 \%)$ of drains were placed to evaluate for normal pressure hydrocephalus. Drains remained in place for a median of 3 days (interquartile range [IQR] 3-3). Patients in all 3 periods had similar risk factors for SSI, but there was a significant difference in length of stay and presence of other drains or hardware (Table 1).

\section{CSF Sampling and PPSA Administration}

Patients in period 1 had a median of 3 (IQR 3-4) CSF samples sent for testing, while patients in periods 2 and 3 had a median of 1 (IQR 1-1) CSF sample sent for testing ( $p$ $<0.001$ ). Patients in periods 1 and 2 received a median of 8 (IQR 8-9) doses of cefazolin and 8 (IQR 5-10) doses of vancomycin, whereas patients in period 3 received a median of 1 (IQR 1-1) dose of cefazolin and 1 (IQR 1-1) dose of vancomycin $(\mathrm{p}<0.001$ and $\mathrm{p}=0.02$, respectively).

\section{Infections}

The infection data are summarized in Table 2. There was no change in the frequency of SSI after discontinuation of routine CSF testing or PPSA ( $0 \%$ in period $1,2 \%$ in period 2 , and $0 \%$ in period 3 ). In fact, only 1 patient $(0.8 \%)$ developed an SSI, and he had a CSF leak after brain surgery and developed an intracranial wound infection that required debridement. In periods 1 and 2, 3 patients developed infections due to resistant organisms and 2 patients had CDI. In period 3, 1 patient had an infection due to a resistant organism. Table 3 shows details of the patients who developed CDI or resistant infections.

\section{Cost and Savings}

Based on our cost calculations, 1) the median cost of CSF tests per patient was \$100.68 (IQR \$100.68-\$134.24) for patients in period 1 and $\$ 33.56$ (IQR \$33.56-\$33.56) in periods 2 and $3(\mathrm{p}<0.001) ; 2)$ the total cost of antibiotics for the 92 patients in periods 1 and 2 was $\$ 2842.79$, 
TABLE 1. Demographic data

\begin{tabular}{|c|c|c|c|c|}
\hline Characteristic & Period 1 & Period 2 & Period 3 & p Value \\
\hline Male, n (\%) & $26(67 \%)$ & $32(60 \%)$ & $20(51 \%)$ & 0.38 \\
\hline Age, median (IQR) & $74(50-79)$ & $69(62-75)$ & $73(66-79)$ & 0.16 \\
\hline Body mass index, mean \pm SD & $27 \pm 4$ & $27 \pm 5$ & $27 \pm 5$ & 1 \\
\hline Diabetes, $n(\%)$ & $8(21 \%)$ & $9(17 \%)$ & $9(23 \%)$ & 0.76 \\
\hline Steroid use prior to placement, $\mathrm{n}(\%)$ & $3(8 \%)$ & $4(8 \%)$ & $4(10 \%)$ & 0.89 \\
\hline Placement in the operating room, $\mathrm{n}(\%)$ & $3(8 \%)$ & $4(8 \%)$ & $3(8 \%)$ & 1 \\
\hline Indication for lumbar drain, $\mathrm{n}(\%)$ & & & & 0.46 \\
\hline Workup for normal pressure hydrocephalus & $26(67 \%)$ & $33(62 \%)$ & $30(77 \%)$ & \\
\hline CSF leak after brain surgery & $8(21 \%)$ & $13(25 \%)$ & $5(13 \%)$ & \\
\hline CSF leak after spine surgery & $2(5 \%)$ & $6(11 \%)$ & $2(5 \%)$ & \\
\hline Intraoperative brain relaxation & $3(8 \%)$ & $1(2 \%)$ & $2(5 \%)$ & \\
\hline Replacement of lumbar drain within 90 days of initial placement, $n(\%)$ & 0 & $1(2 \%)$ & $2(5 \%)$ & 0.24 \\
\hline Other drains or hardware 90 days before or after lumbar drain, $\mathrm{n}(\%)$ & $11(28 \%)$ & $26(49 \%)$ & $21(54 \%)$ & 0.045 \\
\hline Spinal hardware greater than 90 days before lumbar drain & 0 & 0 & 0 & - \\
\hline Spinal hardware 90 days before or after lumbar drain & 0 & $3(6 \%)$ & $3(8 \%)$ & 0.11 \\
\hline Shunt greater than 90 days before lumbar drain & 0 & 0 & $2(5 \%)$ & 0.09 \\
\hline Shunt 90 days before or after lumbar drain & $6(15 \%)$ & $17(32 \%)$ & $14(36 \%)$ & 0.08 \\
\hline External ventricular drain 90 days before or after lumbar drain & 0 & $1(2 \%)$ & 0 & 0.4 \\
\hline Spinal Jackson-Pratt drain 90 days before or after lumbar drain & $2(5 \%)$ & $5(9 \%)$ & $1(3 \%)$ & 0.36 \\
\hline Subdural or subgaleal drain 90 days before or after lumbar drain & $3(8 \%)$ & $3(6 \%)$ & $2(5 \%)$ & 0.88 \\
\hline Total no. of drain days, median (IQR) & $3(3-4)$ & $3(3-4)$ & $3(3-3)$ & 0.49 \\
\hline Length of stay, median (IQR) & $3(3-5)$ & $3(3-7)$ & $3(3-3)$ & 0.02 \\
\hline
\end{tabular}

Period 1: PPSA and daily CSF sampling $(n=39)$; period 2: PPSA and CSF sampling after drain placement then as needed $(n=53)$; and period 3: antibiotics at placement only and CSF sampling after drain placement then as needed $(n=39)$.

Boldface type indicates statistical significance.

whereas the total cost of antibiotics for the 39 patients in period 3 was $\$ 137.80 ; 3)$ the median cost of antibiotics per patient was \$26.32 (IQR \$26.32-\$30.65) in periods 1 and 2 and $\$ 3.29$ (\$3.29-\$3.29) in period $3(\mathrm{p}<0.001) ; 4)$ the cost associated with growth of resistant bacteria and CDI was $\$ 91,291$ in periods 1 and 2 and $\$ 25,573$ in period 3; and 5) on a per patient basis, the total cost associated with antibiotics, CDI, and resistant infections was \$1023.19 in periods 1 and 2 and $\$ 659.25$ in period 3.

\section{Discussion}

Lumbar drain placement is known to have a $3 \%-12 \%$ risk of SSI. ${ }^{10,15,24}$ Infection may occur due to contamination during or after insertion..$^{15}$ Duration of catheterization, leakage, and dysfunction of the drain are known risk factors for SSI for patients with lumbar drains. ${ }^{24}$ Although some institutions administer PPSA and sample CSF daily to evaluate for infection, ${ }^{16,24}$ it was found that frequency of infection remained negligible despite discontinuation of PPSA and daily CSF sampling. To the authors' knowledge, this is the first study addressing the role for routine CSF sampling and PPSA for patients with lumbar drains.

The frequency of CSF monitoring from external ventricular and lumbar drains varies. While some institutions sample CSF daily, others test it only if there are clinical signs or symptoms suggestive of infection (decline in neurological status, fever, headache, leukocytosis, or nuchal rigidity). ${ }^{13,15,17,24}$ Schade et al. found that the value of routine CSF evaluation is limited because CSF studies are comparable in patients with and without infection and no CSF parameter has both sensitivity and specificity greater than $60 \%$ for diagnosis of infection. ${ }^{23}$ Thus, interpretation of CSF results can be challenging and must be done in

\section{TABLE 2. Infection-related data}

\begin{tabular}{|c|c|c|c|c|}
\hline Infection & $\begin{array}{l}\text { Period } \\
1\end{array}$ & $\begin{array}{l}\text { Period } \\
2\end{array}$ & $\begin{array}{l}\text { Period } \\
3\end{array}$ & $\begin{array}{c}\mathrm{p} \\
\text { Value }\end{array}$ \\
\hline Surgical site infections, $\mathrm{n}(\%)$ & 0 & $1(2 \%)$ & 0 & 0.4 \\
\hline Deep infections & 0 & 1 & 0 & \\
\hline Superficial infections & 0 & 0 & 0 & \\
\hline Growth of a resistant organism, $\mathrm{n}(\%)$ & 0 & $3(6 \%)$ & $1(3 \%)$ & 0.18 \\
\hline $\begin{array}{l}\text { Growth of a resistant organism } \\
\text { in blood }\end{array}$ & 0 & 1 & 0 & \\
\hline $\begin{array}{l}\text { Growth of a resistant organism } \\
\text { in urine }\end{array}$ & 0 & 1 & 1 & \\
\hline $\begin{array}{l}\text { Growth of a resistant organism in } \\
\text { sputum }\end{array}$ & 0 & 1 & 0 & \\
\hline CDI, n (\%) & 0 & $2(4 \%)$ & 0 & 0.16 \\
\hline
\end{tabular}

Period 1: PPSA and daily CSF sampling $(n=39)$; period 2: PPSA and CSF sampling after drain placement then as needed $(n=53)$; and period 3: antibiotics at placement only and CSF sampling after drain placement then as needed $(n=39)$. 
TABLE 3. Characteristics of patients with CDI or resistant infections within 90 days of drain placement

\begin{tabular}{|c|c|c|c|c|c|c|}
\hline Infection & Period & $\begin{array}{l}\text { Age } \\
\text { (yrs) }\end{array}$ & Sex & $\begin{array}{l}\text { Antibiotic } \\
\text { Prophylaxis }\end{array}$ & $\begin{array}{l}\text { No. of Doses } \\
\text { of Prophylaxis }\end{array}$ & $\begin{array}{c}\text { Time Btwn Drain } \\
\text { Placement \& Infection }\end{array}$ \\
\hline Enterobacter cloacae in sputum resistant to cefazolin & 2 & 68 & Male & Cefazolin & 7 & 1 month \\
\hline Escherichia coli bacteremia resistant to cefazolin & 2 & 72 & Female & Cefazolin & 8 & 1 month \\
\hline Citrobacter freundii complex urinary tract infection resistant to cefazolin & 2 & 71 & Male & Cefazolin & 8 & 1 month \\
\hline $\mathrm{CDI}$ & 2 & 82 & Female & Vancomycin & 6 & 2 months \\
\hline CDI & 2 & 61 & Male & Vancomycin & 5 & 1 week \\
\hline Escherichia coli urinary tract infection resistant to cefazolin & 3 & 87 & Male & Cefazolin & 1 & 3 weeks \\
\hline
\end{tabular}

conjunction with consideration of the clinical picture. If CSF studies are performed routinely and are abnormal, it is necessary to decide how to proceed based on the patient's appearance, to empirically start antibiotics, or to ignore the results. If CSF studies are only sent when a patient shows signs or symptoms of infection and the results are abnormal, it is clear that treatment is needed. As such, one could argue that it is not necessary to send CSF at the time of drain placement if a patient does not appear to be infected, but this is part of institutional protocol to provide a basis of comparison should the need arise to send future CSF studies.

The role of PPSA for patients with external ventricular drains has been evaluated extensively, but the need for PPSA for patients with lumbar drains has not been explored. ${ }^{10,15,17}$ Numerous single-center studies demonstrated that use of PPSA does not correlate with frequency of infection in patients with external ventricular drains, ${ }^{4,5,8,11}$ but a systematic review by Sonabend et al. showed a protective effect of PPSA in this population. ${ }^{25}$ However, due to the advent of antibiotic-impregnated and silver-impregnated external ventricular drain catheters, this literature cannot be directly extrapolated to the lumbar drain patient population given that only conventional catheters are used for lumbar drainage. ${ }^{17}$

Guidance on use of PPSA is provided by numerous medical societies, including the World Health Organization, the American Society of Health-System Pharmacists, the Infectious Diseases Society of America, the Surgical Infection Society, and the Society for Healthcare Epidemiology of America, all of whom denounced the administration of PPSA after neurosurgical procedures until all drains are removed. ${ }^{3,6}$ Nonetheless, in a survey of the Neurocritical Care Society, $46 \%$ of respondents reported that their institution routinely administers PPSA to patients with lumbar drains. Interestingly, only $22 \%$ of respondents believed PPSA should be administered to this population. ${ }^{16}$

In addition to the fact that our infection frequency was low both with and without use of daily antibiotics, frequencies of CDI and growth of resistant bacteria were higher during the periods in which PPSA was administered. The association between antibiotic use and both CDI and growth of resistant organisms is well known.,11,12,14,20-22 Injudicious antibiotic use can lead to development of genes encoding for resistance, which are dangerous not only to an individual patient, but also to the health care system and the community. who did not receive PPSA grew a resistant organism.
Infection prevention can best be achieved through a multidisciplinary effort to create and use a detailed protocol for drain placement, CSF sampling, technical and hygienic aspects of drain management, and drain removal. ${ }^{13,15}$ All staff who interact with patients with lumbar drains should be educated on the protocol, and surveillance rounds should be conducted to confirm that drains are appropriately dressed and managed. ${ }^{13}$ Lumbar drains should be placed in a sterile environment by a health care worker wearing a gown, cap, mask and sterile gloves. ${ }^{15}$ Drains should be removed as soon as possible to prevent contamination with skin flora. ${ }^{24}$ Perioperative antibiotic prophylaxis should be administered, but the present results demonstrate that PPSA and daily CSF monitoring is not necessary. ${ }^{15}$

These findings represent a single-institution retrospective observational study and the sample size is small, so of course, firm conclusions cannot be made. A large prospective multicenter study would provide more convincing data. If there is truly no difference in the frequency of SSI after lumbar drain placement if antibiotics are given only during drain placement and CSF sampling is done once after placement and either 1) antibiotics are given and CSF sampling is performed daily until the drain is removed or 2) antibiotics are given until the time of drain removal but CSF sampling is performed only once after placement then as needed, and the rate of SSI is assumed to be $2 \%$ in both groups, then a binary outcome equivalence trial would require 16,973 patients in each arm to be $90 \%$ sure that the limits of a 2 -sided $90 \%$ confidence interval would exclude a difference in the frequency of SSI between the 2 groups of more than $0.5 \%$ (https://www.sealedenvelope. com/power/binary-equivalence/). Patients may have been hospitalized elsewhere with an SSI or CDI or resistant bacteria in the 90 days after drain placement, but one could expect that the patient would ultimately follow up with the surgeon who performed their procedure, so this would be documented in the medical record. Lastly, the financial benefits of not using prolonged antibiotics may be underestimated given that the cost analysis is extrapolated and higher doses of antibiotics cost more money, but antibiotic doses were not recorded.

\section{Conclusions}

Use of PPSA and routine CSF sampling appears to be unnecessary and harmful to patients with lumbar drains who have no evidence of ventriculitis. After discontinuing daily antibiotics and daily CSF sampling for patients with 
lumbar drains at the authors' institution, frequency of SSI was unchanged and frequency of antibiotic-related complications decreased.

\section{References}

1. Abu Hamdeh S, Lytsy B, Ronne-Engström E: Surgical site infections in standard neurosurgery procedures- a study of incidence, impact and potential risk factors. Br J Neurosurg 28:270-275, 2014

2. Akalin HE: Surgical prophylaxis: the evolution of guidelines in an era of cost containment. J Hosp Infect 50 (Suppl A):S3-S7, 2002

3. Allegranzi B, Zayed B, Bischoff P, Kubilay NZ, de Jonge S, de Vries F, et al: New WHO recommendations on intraoperative and postoperative measures for surgical site infection prevention: an evidence-based global perspective. Lancet Infect Dis 16:e288-e303, 2016

4. Alleyne CH Jr, Hassan M, Zabramski JM: The efficacy and cost of prophylactic and perioprocedural antibiotics in patients with external ventricular drains. Neurosurgery 47:1124-1129, 2000

5. Blomstedt GC: Results of trimethoprim-sulfamethoxazole prophylaxis in ventriculostomy and shunting procedures. A double-blind randomized trial. J Neurosurg 62:694-697, 1985

6. Bratzler DW, Dellinger EP, Olsen KM, Perl TM, Auwaerter PG, Bolon MK, et al: Clinical practice guidelines for antimicrobial prophylaxis in surgery. Am J Health Syst Pharm 70:195-283, 2013

7. Centers for Disease Control: CDC/NHSN Surveillance Definitions for Specific Types of Infections. (https://www. cdc.gov/nhsn/pdfs/pscmanual/17pscnosinfdef_current.pdf) [Accessed January 19, 2018]

8. Clark WC, Muhlbauer MS, Lowrey R, Hartman M, Ray MW, Watridge CB: Complications of intracranial pressure monitoring in trauma patients. Neurosurgery 25:20-24, 1989

9. Collignon P: Antibiotic resistance: are we all doomed? Intern Med J 45:1109-1115, 2015

10. Coplin WM, Avellino AM, Kim DK, Winn HR, Grady MS: Bacterial meningitis associated with lumbar drains: a retrospective cohort study. J Neurol Neurosurg Psychiatry 67:468-473, 1999

11. Dellit TH, Chan JD, Fulton C, Pergamit RF, McNamara EA, Kim LJ, et al: Reduction in Clostridium difficile infections among neurosurgical patients associated with discontinuation of antimicrobial prophylaxis for the duration of external ventricular drain placement. Infect Control Hosp Epidemiol 35:589-590, 2014

12. Flibotte JJ, Lee KE, Koroshetz WJ, Rosand J, McDonald CT: Continuous antibiotic prophylaxis and cerebral spinal fluid infection in patients with intracranial pressure monitors. Neurocrit Care 1:61-68, 2004

13. Hepburn-Smith M, Dynkevich I, Spektor M, Lord A, Czeisler B, Lewis A: Establishment of an external ventricular drain best practice guideline: the quest for a comprehensive, universal standard for external ventricular drain care. J Neurosci Nurs 48:54-65, 2016

14. Lemaire A, Dombrovskiy V, Batsides G, Scholz P, Solina A, Brownstone N, et al: The effect of Clostridium difficile infection on cardiac surgery outcomes. Surg Infect (Larchmt) 16:24-28, 2015

15. Leverstein-van Hall MA, Hopmans TE, van der Sprenkel JW, Blok HE, van der Mark WA, Hanlo PW, et al: A bundle approach to reduce the incidence of external ventricular and lumbar drain-related infections. J Neurosurg 112:345-353, 2010

16. Lewis A, Czeisler BM, Lord AS: Prolonged prophylactic antibiotics with neurosurgical drains and devices: Are we us- ing them? Do we need them? Am J Infect Control 44:17571758,2016

17. Lewis A, Czeisler BM, Lord AS: Variations in strategies to prevent ventriculostomy-related infections: a practice survey. Neurohospitalist 7:15-23, 2017

18. Lewis A, Sen R, Hill TC, James H, Lin J, Bhamra H, et al: Antibiotic prophylaxis for subdural and subgaleal drains. J Neurosurg 126:908-912, 2017

19. Magee G, Strauss ME, Thomas SM, Brown H, Baumer D, Broderick KC: Impact of Clostridium difficile-associated diarrhea on acute care length of stay, hospital costs, and readmission: a multicenter retrospective study of inpatients, 2009-2011. Am J Infect Control 43:1148-1153, 2015

20. May AK, Fleming SB, Carpenter RO, Diaz JJ, Guillamondegui OD, Deppen SA, et al: Influence of broad-spectrum antibiotic prophylaxis on intracranial pressure monitor infections and subsequent infectious complications in head-injured patients. Surg Infect (Larchmt) 7:409-417, 2006

21. Murphy RKJ, Liu B, Srinath A, Reynolds MR, Liu J, Craighead MC, et al: No additional protection against ventriculitis with prolonged systemic antibiotic prophylaxis for patients treated with antibiotic-coated external ventricular drains. J Neurosurg 122:1120-1126, 2015

22. Roberts RR, Hota B, Ahmad I, Scott RD II, Foster SD, Abbasi F, et al: Hospital and societal costs of antimicrobial-resistant infections in a Chicago teaching hospital: implications for antibiotic stewardship. Clin Infect Dis 49:1175-1184, 2009

23. Schade RP, Schinkel J, Roelandse FWC, Geskus RB, Visser LG, van Dijk JM, et al: Lack of value of routine analysis of cerebrospinal fluid for prediction and diagnosis of external drainage-related bacterial meningitis. J Neurosurg 104:101108, 2006 (Erratum in J Neurosurg 106:941, 2007)

24. Schade RP, Schinkel J, Visser LG, Van Dijk JMC, Voormolen JHC, Kuijper EJ: Bacterial meningitis caused by the use of ventricular or lumbar cerebrospinal fluid catheters. J Neurosurg 102:229-234, 2005

25. Sonabend AM, Korenfeld Y, Crisman C, Badjatia N, Mayer SA, Connolly ES Jr: Prevention of ventriculostomy-related infections with prophylactic antibiotics and antibiotic-coated external ventricular drains: a systematic review. Neurosurgery 68:996-1005, 2011

26. Williams TA, Leslie GD, Dobb GJ, Roberts B, van Heerden PV: Decrease in proven ventriculitis by reducing the frequency of cerebrospinal fluid sampling from extraventricular drains. J Neurosurg 115:1040-1046, 2011

27. Williamson RA, Phillips-Bute BG, McDonagh DL, Gray MC, Zomorodi AR, Olson DM, et al: Predictors of extraventricular drain-associated bacterial ventriculitis. J Crit Care 29:77-82, 2014

\section{Disclosures}

The authors report no conflict of interest concerning the materials or methods used in this study or the findings specified in this paper.

\section{Author Contributions}

Conception and design: Lewis, Pacione. Acquisition of data: Lewis, Rothstein. Analysis and interpretation of data: Lewis. Drafting the article: Lewis. Critically revising the article: Rothstein, Pacione. Reviewed submitted version of manuscript: all authors. Approved the final version of the manuscript on behalf of all authors: Lewis. Statistical analysis: Lewis.

\section{Correspondence}

Ariane Lewis: NYU Langone Medical Center, New York, NY. ariane.kansas.lewis@gmail.com. 